\title{
COMPARISON OF 2D GRID SIMULATIONS FOR FLOW PAST CYLINDER AT HIGH REYNOLDS NUMBERS
}

\author{
Lenka LAUSOVÁ ${ }^{1,{ }^{*}}$, Ivan KOLOŠ ${ }^{1}$, Vladimíra MICHALCOVÁ ${ }^{1}$ \\ 1 Faculty of Civil Engineering, VŠB - Technical University of Ostrava, 17. listopadu 2172/15, \\ 70800 Ostrava - Poruba, Czech Republic. \\ corresponding author: lenka.lausova@vsb.cz.
}

\begin{abstract}
The paper focuses on the verification of the suitability of the SST $k-\omega$ model on the flow past a circular cylinder in 2D for a high Reynolds number. The study compares the results of drag and lifts coefficients with respect to different types of meshes and time steps. The mean velocity field in the wake region behind the cylinder is evaluated and compared to experimental data available from literature. The numerical simulations are solved using CFD codes in the ANSYS Fluent software and use the finite volume method.
\end{abstract}

\section{Keywords:}

CFD simulation;

High Reynolds number;

Drag coefficient;

Lift coefficient;

Mean velocity field.

\section{Introduction}

Flow past a circular cylinder has been investigated in a large number of papers. It has been the subject of both experimental and numerical studies. Although the geometry is relatively simple, the physics is extremely complex and has been the subject of research in many workplaces over the years [1 - 4]. Analysis in this paper aims to validate suitable numerical model in $2 \mathrm{D}$ on the flow past a smooth circular cylinder for $\mathrm{Re}=1.7 \cdot 10^{4}[-]$.

RANS models based on the time averaging of Navier-Stokes equations are the most commonly used tool for most engineering tasks of turbulent flows. There are various RANS models, for which the SST $k-\omega$ model has been chosen to solve the task of the flow past a cylinder in 2D. This model is highly recommended for numerical modelling at high Reynolds numbers [5].

The current numerical study is solved using CFD codes in the ANSYS Fluent software and focuses on the evaluation of drag and lift coefficients of the flow past the cylinder for four different grids. The velocity field in the wake is monitored and evaluated. Experimental data such as drag coefficient or the velocity field in the wake are available from literature and used for the comparative study, the time-step size effect and grid shape effect are discussed.

\section{Task description}

This paper focuses on the verification of SST $k-\omega$ model on the flow past a circular cylinder for four different grids in 2D. Computational area is presented in Fig. 1.

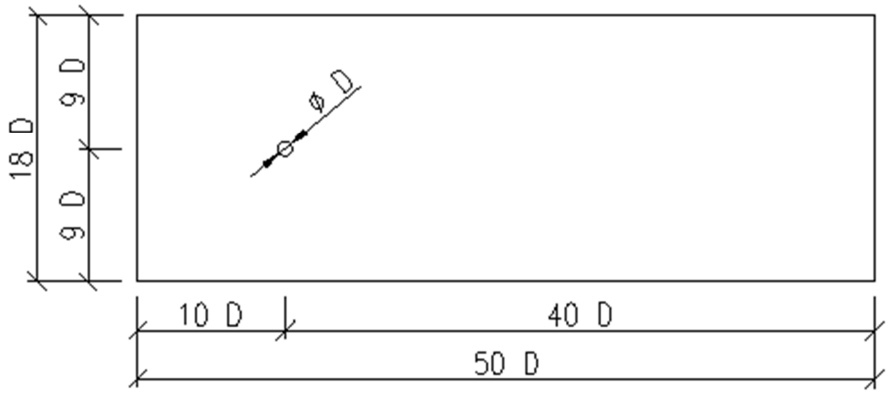

Fig. 1: Computational area - dimensions. 
The basic parameters for flow past a circular cylinder are listed in the following Table 1.

Table 1: Parameters of the calculations.

\begin{tabular}{|c|c|c|c|}
\hline Geometric dimensions & Values & $\begin{array}{c}\text { Parameters of the } \\
\text { calculations }\end{array}$ & Values \\
\hline Cylinder diameter & $D=0.1 \mathrm{~m}$ & Air velocity inlet & $u_{0}=3 \mathrm{~m} \cdot \mathrm{s}^{-1}$ \\
\hline Length of the area & $L=5 \mathrm{~m}$ & Turbulence intensity & $i_{u}=2 \%$ \\
\hline Width of the area & $B=1.8 \mathrm{~m}$ & Kinematic viscosity & $v=1.7 \cdot 10^{-5} \mathrm{~m}^{-2} \mathrm{~s}^{-1}$ \\
\hline $\begin{array}{c}\text { Distance of cylinder axis from } \\
\text { inlet }\end{array}$ & $l=1.0 \mathrm{~m}$ & Density & $\rho=1.225 \mathrm{~kg} \cdot \mathrm{m}^{-3}$ \\
\hline
\end{tabular}

The flow past a cylinder is very sensitive to the changes of the Reynolds number, which is a dimensionless parameter representing the ratio of inertia force to viscous force in a flow [5]. The Reynolds number for this task is

$\operatorname{Re}=\frac{u \cdot D}{v}=\frac{3 \cdot 0.1}{1.7 \cdot 10^{-5}}=1.7 \cdot 10^{4}$,

where $u\left[\mathrm{~m} \cdot \mathrm{s}^{-1}\right]$ represents the flow velocity, $v\left[\mathrm{~m}^{-2} \cdot \mathrm{s}^{-1}\right]$ is kinematical viscosity of the running fluid and $D[\mathrm{~m}]$ is a diameter of the cylinder. The value $\mathrm{Re}=1.7 \cdot 10^{4}$ represents a fully developed turbulence in the subcritical regime.

\subsection{Meshing}

In the current work there are tested four types of computational 2D meshes: tri-67, tri-72, qua-35, qua-48. The names express the cell shape and number of cells in thousands. The grids are shown in Figs. 2 - 4.

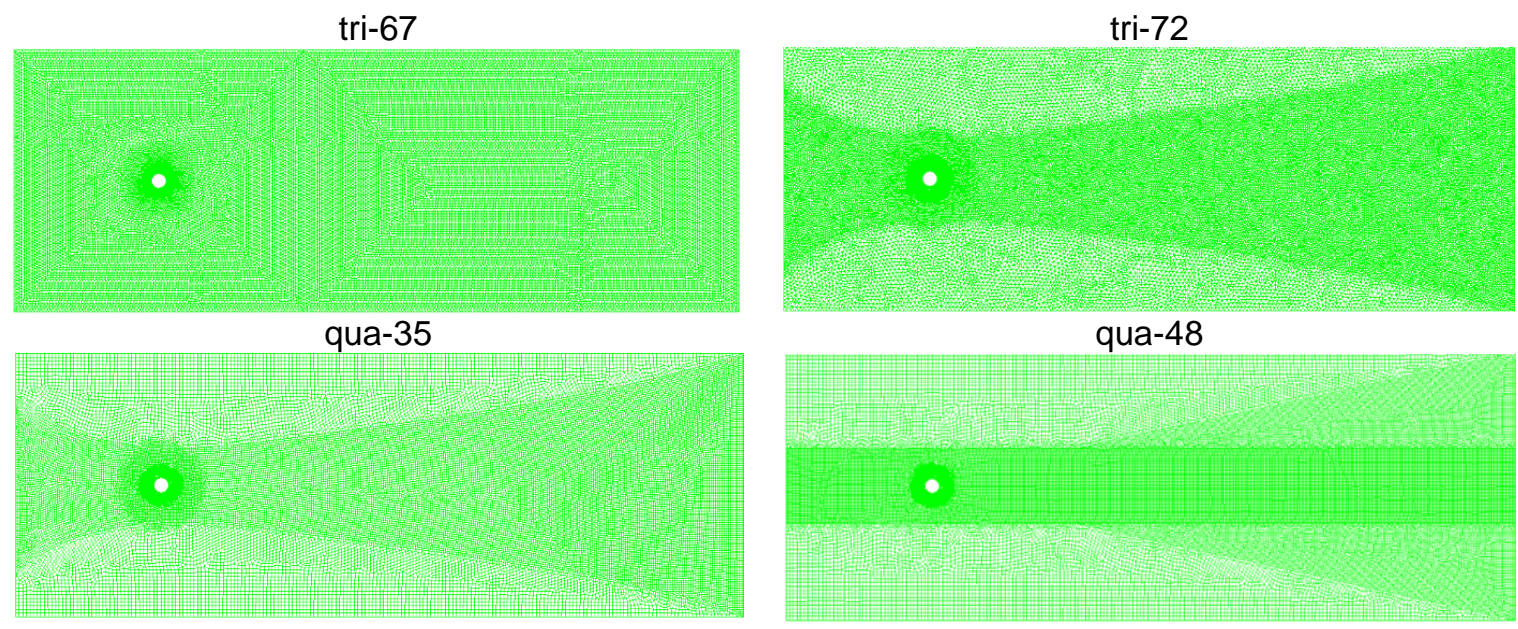

Fig. 2: Full mesh.

tri-67

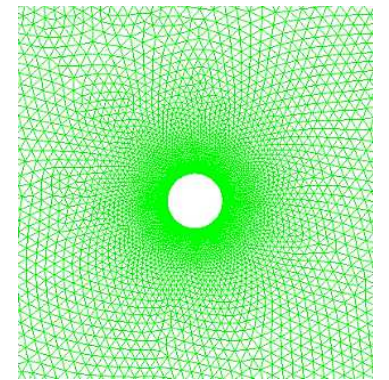

$\operatorname{tri}-72$

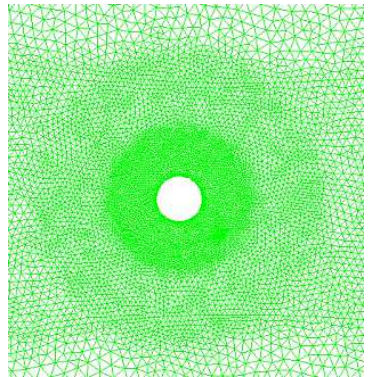

qua-35

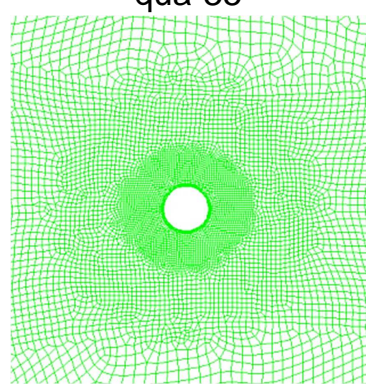

qua-48

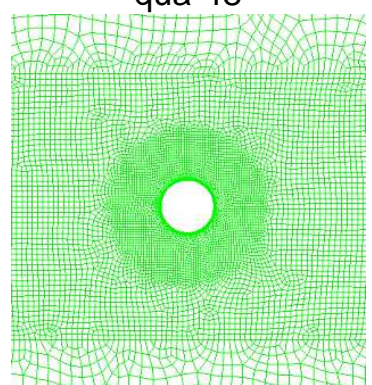

Fig. 3: Mesh - details of grids in the near surroundings of the cylinder. 

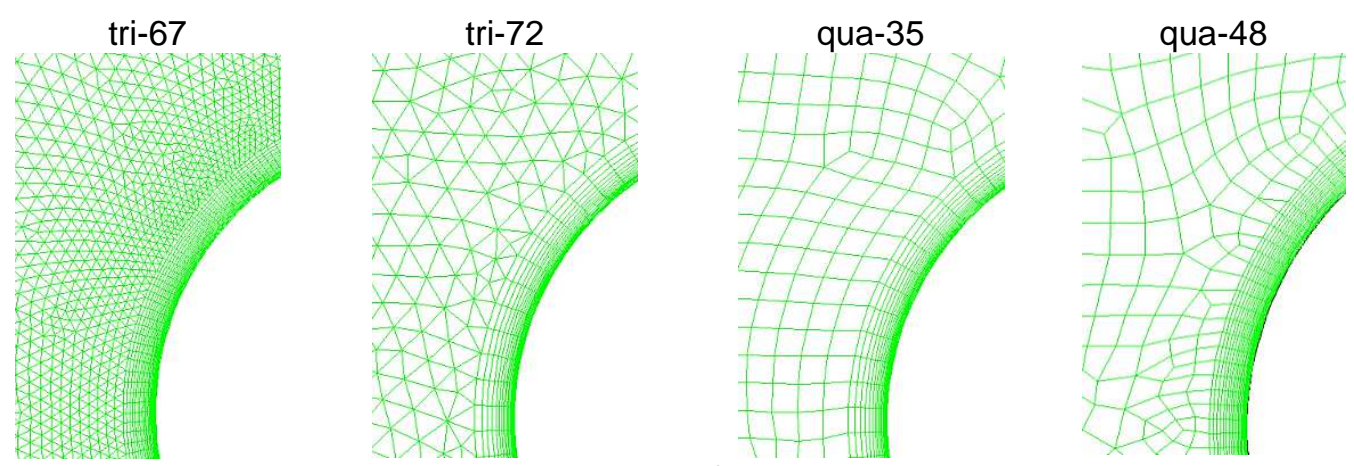

Fig. 4: Mesh - details of the cylinder wall.

Two grids are hybrid and consist of mainly triangular cells (tri-67, tri-72) and two grids are formed with quadrilateral cells (qua-35, qua-48). Prismatic boundary layer near the wall at tri-67 and tri-72 grids is from quadrilateral cells, which are further transformed into triangular cells. All grids have fine meshes where $y+<1$, so near wall modelling approach is used [6]. Detailed description of the flow past the wall of the cylinder including the viscous sublayer is related to the fineness of the mesh. There is supposed to be prepared a detailed meshing of inner layers which means that the radial height of the mesh cells at the wall is sufficiently reduced. There is a different way of creating grids. The most gradual transition from the boundary layer is made at the tri-67 grid (Fig. 2). The transition from prismatic layer of all meshes can be seen in Figs. 2 - 4. Details of grids in the near surroundings of the cylinder are shown in Fig. 3. Fig. 4 shows detailed cell distribution in the boundary layer.

Detailed description of the grids:

- Mesh tri-67 (Fig. 2) consists of 66900 triangular cells. Cell size near the wall is $0.001 D(D$ is a diameter of the cylinder). Size of the mesh cells gradually grows up to $0.02 D$, while grow rate is 1.1 (Fig.3). After reaching the size $0.02 \mathrm{~m}$, the cells stay at that size. A prismatic layer near the wall is also presented (Fig. 4). Size of the cells at the wall is $0.1 \mathrm{~mm}$, the thickness of the boundary layer is 5.7 $\mathrm{mm}$, and there are 20 prism layers.

- Grid tri-72 (Fig. 2) consists of 71800 triangular cells. Cell size within the windward and leeward area is around $15 \mathrm{~mm}$, i.e. $0.15 D$ and it gradually decreases down to $5 \mathrm{~mm}(0.05 D)$ in the close vicinity of the cylinder wall (Fig. 3). Cell size of the largest element does not exceed $0.025 D$. A prismatic layer with the growth rate 1.2 is created around the wall to enhance near wall treatment (Fig. 4). Size of the cells at the wall is $0.01 \mathrm{~mm}$, the thickness of the boundary layer is $6.8 \mathrm{~mm}$, and there are 30 prism layers.

- Mesh qua-35 (Fig. 2) is quadrilateral dominant and consists of 34900 cells. Basic size setup, before the mesh is generated, is similar to the mesh tri-72: elements in critical windward/leeward area have size $0.15 D$, the smallest elements close to the wall have size $0.05 \mathrm{D}$ (Fig. 3). As well as previous meshes, the mesh qua-35 includes prismatic layer (Fig. 4) that is composed of 30 layers, applied growth rate is 1.2 . The size of the cells at the wall is $0.1 \mathrm{~mm}$, the thickness of the boundary layer is 5.6 $\mathrm{mm}$, and there are 30 prism layers.

- Mesh qua-48 (Fig. 2) is composed of 48700 cells, mostly quadrilateral. Distribution of the smallest cells is concentrated in the strip that surrounds cylinder (Fig. 3). Height of the first cell in the prismatic layer is $0.001 D$ (Fig. 4), growth rate is 1.1 , and the number of layers is 20 . Element size varies between $0.05 \mathrm{D}$ to $0.15 \mathrm{D}$ in refinement areas. The biggest elements of the mesh have size $0.25 \mathrm{D}$. The size of the cells at the wall is $0.01 \mathrm{~mm}$, the thickness of the boundary layer is $5.7 \mathrm{~mm}$, and there are 20 prism layers.

\subsection{Numerical model}

RANS models unable the most economic approach to compute complex turbulent flows. These models introduce turbulent viscosity to determine the Reynolds Stresses and simplify the problem to the solution of additional transport equations. RANS model SST $k-\omega$, which is used for this numerical simulation, solves two additional transport equations for the kinetic energy of the turbulence $k$ and kinetic energy dissipation $\omega$. Turbulent viscosity is calculated as a function of $k$ and $\omega[7,8]$. Numerical simulations of the current task are solved in the ANSYS Fluent.

Boundary conditions are identical for all calculations, on the input it is the velocity-inlet, on the output it is the pressure-outlet. The boundary conditions on the lower and upper edge of the 
computing area are defined so they would correspond to the aerodynamic tunnel boundary for eventually further comparison with experimental results.

\section{Problem solving}

The aim of the study is an evaluation of drag coefficients, lift coefficients and the mean velocity fields in the wake and their comparison to experimental data from literature [1]. The effect of the timestep size and grid shapes are observed.

The drag coefficient $c_{d}$ is based on the sum of the pressure force and the viscous force components on the cylinder surface acting in the horizontal direction [5]. According to [1] for $R e=$ $1.7 \cdot 10^{4}[-]$ the drag coefficient approaches 1.2 .

The lift coefficient $c_{l}$ is calculated similarly like $c_{d}$ but vertical force is considered rather than the horizontal one. The lift coefficient should symmetrically oscillate in the maximal range of $c_{l} \epsilon$ $(-1,+1)[1]$

\subsection{Time-step size effect on the drag and lift coefficient}

The grids are evaluated for the effect of time step change on the resulting $c_{d}$ or $c_{l}$ coefficient. Time step $\Delta t[\mathrm{~s}]$ should be based on the Strouhal number St which is a dimensionless parameter describing the shedding of the vortices in the wake region of a flow. It relates the frequency of vortex shedding to the incident wind speed according to the formula

St $=\frac{f \cdot D}{u}$,

where $D[\mathrm{~m}]$ is a diameter of the cylinder, $u\left[\mathrm{~m} \cdot \mathrm{s}^{-1}\right]$ is the velocity of the flow, and $f=1 / T$ is called the Strouhal frequency where $T$ denotes for period [5]. The Strouhal number for the cylinder corresponds to the value $\mathrm{St} \approx 0.2$ [1], the period then is $T=0.17 \mathrm{~s}$. Recommended time step is $10-20$ times smaller than the period $T$ value [9], so the time step should be set in the range $\Delta t \epsilon(0.017,0.0085) \mathrm{s}$.

Table 2: Computational results of drag and lift coefficient for different time steps.

\begin{tabular}{|c|c|c|c|c|c|}
\hline & grid & $\begin{array}{c}\text { time step } \\
{[\mathrm{s}]}\end{array}$ & $\begin{array}{c}\text { drag coefficient } \\
{[-]} \\
\end{array}$ & $\begin{array}{l}\text { average drag } \\
\text { coefficient [-] }\end{array}$ & $\begin{array}{c}\text { lift coefficient } \\
{[-]}\end{array}$ \\
\hline \multirow{4}{*}{ tri- 67} & \multirow{4}{*}{ triangular } & 0.001 & $1.25-1.42$ & 1.33 & $(-1.5,1.5)$ \\
\hline & & 0.0025 & $1.13-1.26$ & 1.20 & $(-1.2,1.2)$ \\
\hline & & 0.003 & $1.09-1.19$ & 1.14 & $(-1.0,1.0)$ \\
\hline & & 0.0035 & $0.95-0.99$ & 0.97 & $(-0.5,0.5)$ \\
\hline \multirow{4}{*}{ tri-72 } & \multirow{4}{*}{ triangular } & 0.001 & $1.27-1.50$ & 1.38 & $(-1.6,1.55)$ \\
\hline & & 0.005 & $1.23-1.48$ & 1.35 & $(-1.6,1.55)$ \\
\hline & & 0.008 & $1.20-1.45$ & 1.32 & $(-1.5,1.45)$ \\
\hline & & 0.017 & $1.14-1.43$ & 1.28 & $(-1.4,1.35)$ \\
\hline \multirow{4}{*}{ qua- 35} & \multirow{4}{*}{ quadrilateral } & 0.001 & $1.22-1.44$ & 1.33 & $(-1.4,1.4)$ \\
\hline & & 0.005 & $1.14-1.35$ & 1.25 & $(-1.2,1.2)$ \\
\hline & & 0.008 & $1.13-1.34$ & 1.23 & $(-1.2,1.2)$ \\
\hline & & 0.017 & $1.08-1.32$ & 1.20 & $(-1.2,1.2)$ \\
\hline \multirow{4}{*}{ qua- 48} & \multirow{4}{*}{ quadrilateral } & 0.001 & $1.27-1.45$ & 1.36 & $(-1.5,1.4)$ \\
\hline & & 0.003 & $1.23-1.40$ & 1.32 & $(-1.5,1.4)$ \\
\hline & & 0.005 & $1.2-1.37$ & 1.29 & $(-1.3,1.3)$ \\
\hline & & 0.008 & $1.15-1.30$ & 1.22 & $(-1.2,1.2)$ \\
\hline
\end{tabular}


The results of drug $\left(c_{d}\right)$ or lift $\left(c_{l}\right)$ coefficients for four different time steps from the recommended interval are evaluated for all grids. Time steps could not be set identical for all grids due to convergence. The best $c_{d}$ coefficient results $\left(c_{d} \approx 1.2\right)$ of the tri-72 and qua-35 grids are for the border time step $\Delta t=0.017$, while for the tri- 67 and qua- 48 grids, due to convergence smaller steps have to be chosen (Table 2). The dependence of the time step change to the $c_{d}$ values for individual grids is graphically displayed in the graph in Fig. 5.

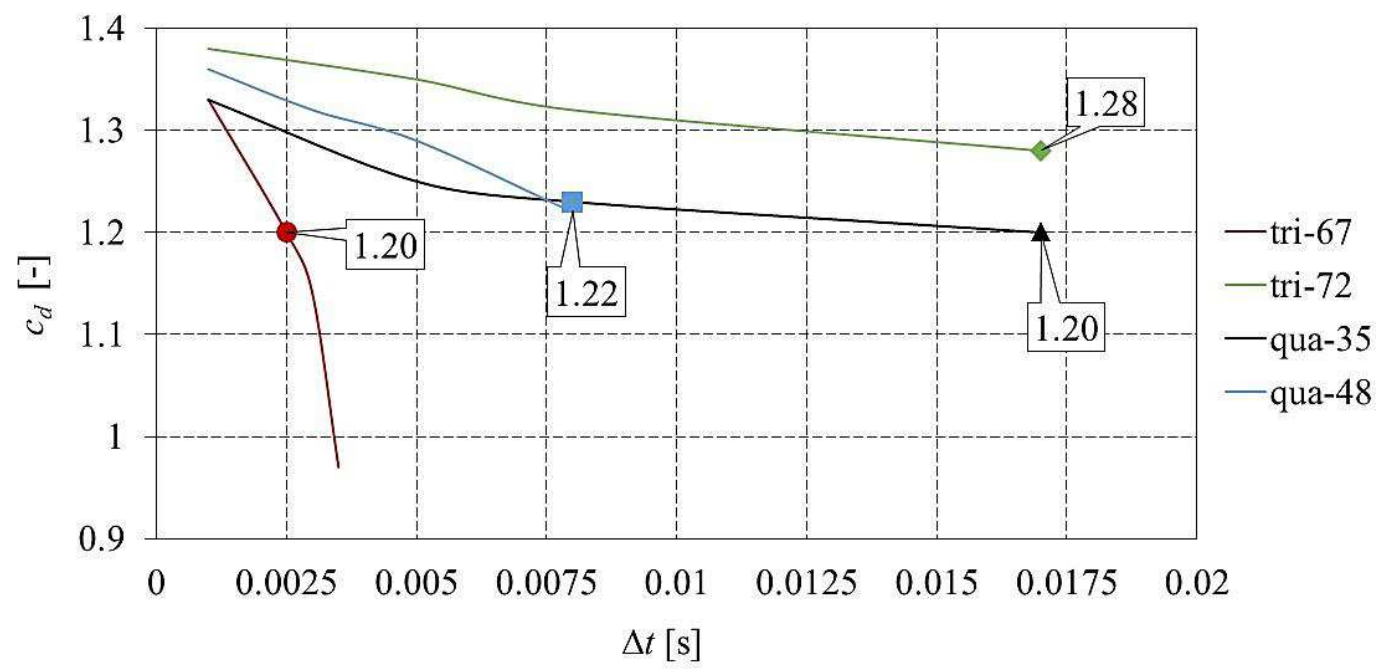

Fig. 5: The variability of the mean $c_{d}$ value depending on the time step.

The dependence of the selected time step on the lift coefficient is obvious from Table 2. The $c_{l}$ values increase with a decreasing time step. As discussed above, the results of the oscillation of lift traces should be symmetrical and oscillate in interval $c_{l} \in(-1,+1)$. This requirement of oscillation symmetry is reached for all tested grids, except for the tri-72 grid where the time recording is slightly unbalanced. The recommended interval for the lift coefficient is exceeded in some cases.

The following Table 3 summarizes the selected time steps for individual grids for which the evaluation of drag coefficient $\left(c_{d}\right)$ and lift coefficient $\left(c_{l}\right)$ are performed.

Table 3: Selected cases of grids for analysis.

\begin{tabular}{|c|c|c|c|c|}
\hline grid & $\begin{array}{c}\text { time step } \\
{[\mathrm{s}]}\end{array}$ & $\begin{array}{c}\text { drag coefficient } \\
{[-]}\end{array}$ & $\begin{array}{c}\text { average drag } \\
\text { coefficient [-] }\end{array}$ & $\begin{array}{c}\text { lift coefficient } \\
{[-]}\end{array}$ \\
\hline tri-67 & 0.0025 & $1.13-1.26$ & 1.20 & $(-1.2,1.2)$ \\
\hline tri-72 & 0.017 & $1.14-1.43$ & 1.28 & $(-1.4,1.35)$ \\
\hline qua-35 & 0.017 & $1.08-1.32$ & 1.20 & $(-1.2,1.2)$ \\
\hline qua-48 & 0.008 & $1.15-1.30$ & 1.22 & $(-1.2,1.2)$ \\
\hline
\end{tabular}

The Fig. 6 and Fig. 7 present time records of drag and lift coefficients from numerical simulations of the selected cases and correspond with the Table 3 . The oscillation of the drag and lift traces from graphs is obvious. 

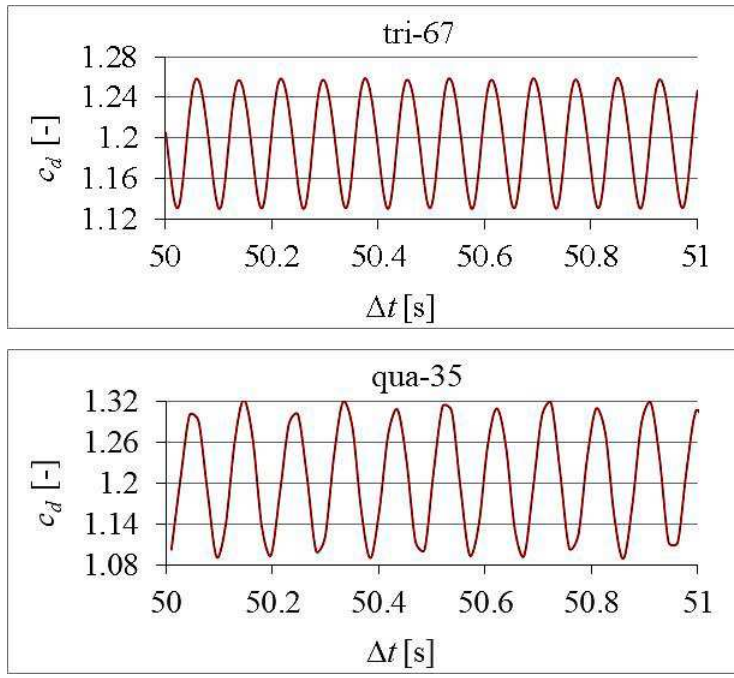

tri- 72

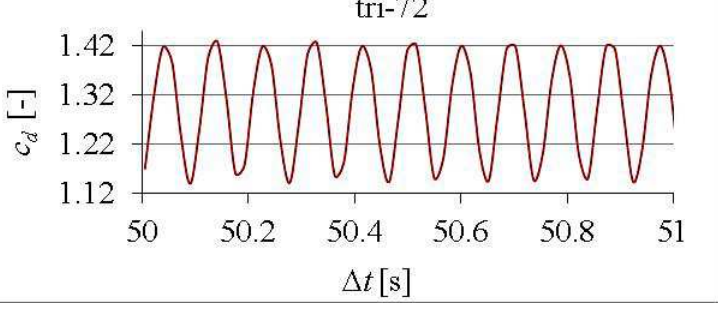

qua-48

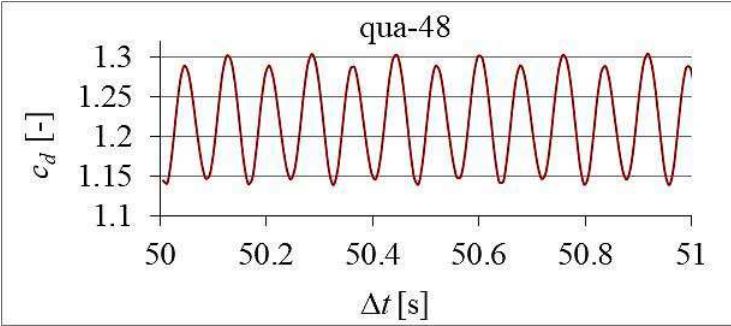

Fig. 6: Time record of drag coefficient for selected cases from Table 3.
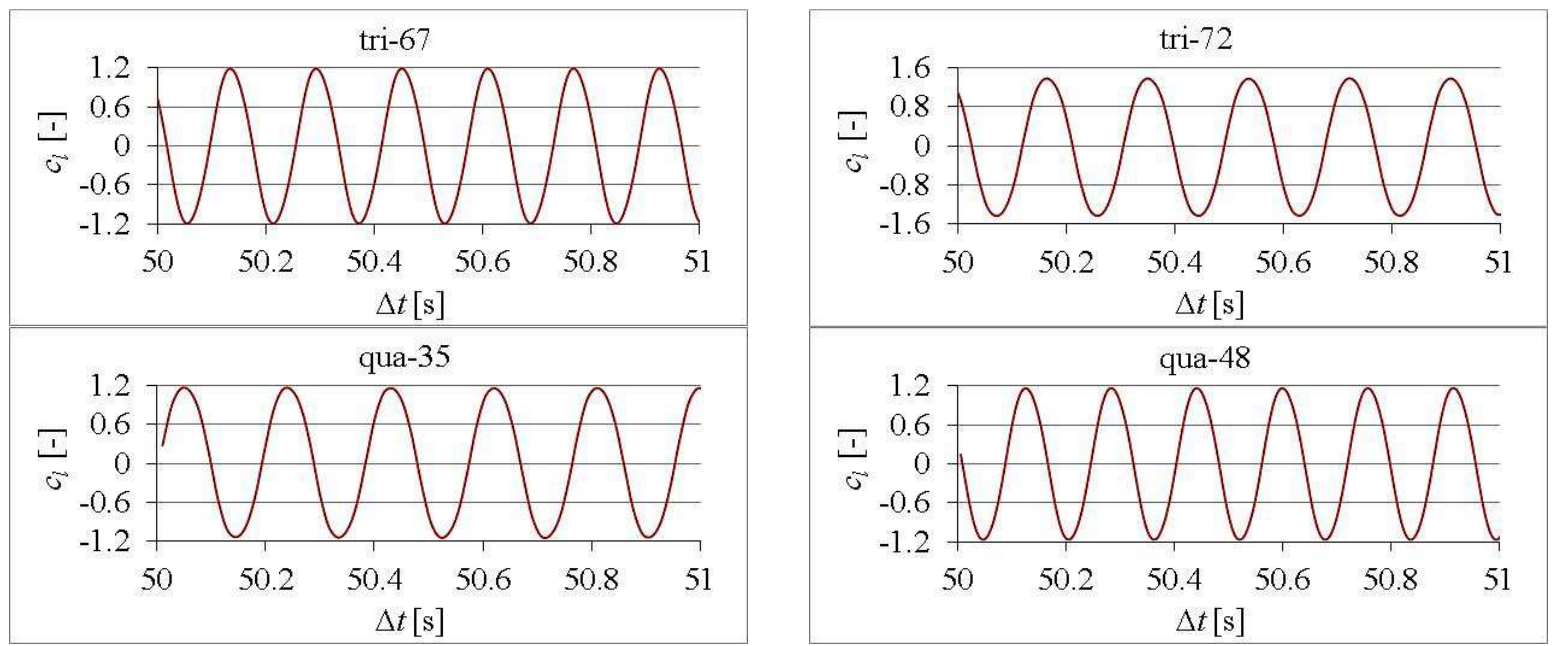

Fig. 7: Time record of lift coefficient for selected cases from Table 3.

\subsection{Grid shape effect on the drag and lift coefficient}

As described above, the grids are different in the shape of cells (triangular/quadrilateral) and also in the way of meshing. Near wall modelling approach is used for all grids. With the respect to the value of the drag coefficient $c_{d} \approx 1.2$, the grids tri- 67 and qua- 35 seem to be the best. From the point of view of the lift coefficient interval $c_{l} \in(-1,1)$, the worst results show the mesh tri-72, where the slightly unsymmetrical lift coefficient even occurs.

\subsection{Velocity field in the wake}

In this study the mean stream velocity field in the wake region behind the cylinder is evaluated. The following figures Fig. 8 and Fig. 9 are for illustration only and show the course of the mean stream velocity and velocity $x$ for calculated grids. 

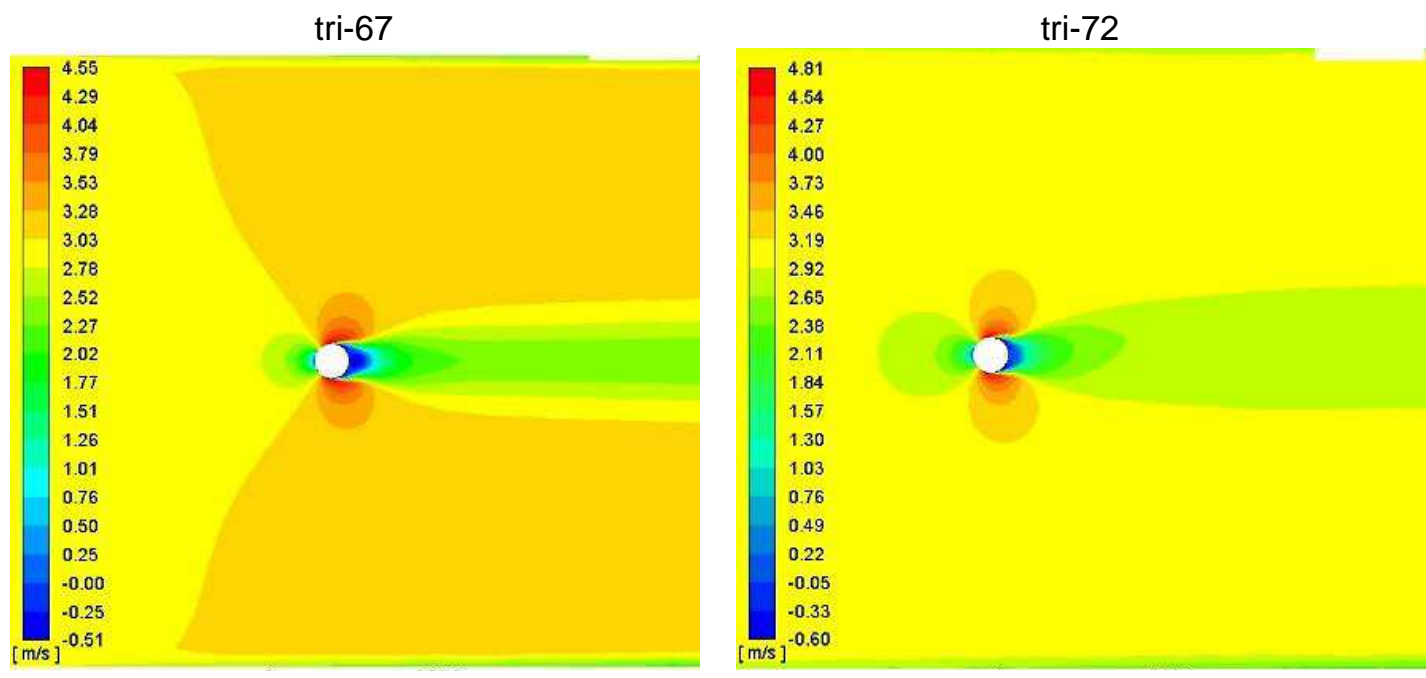

qua-35

qua-48
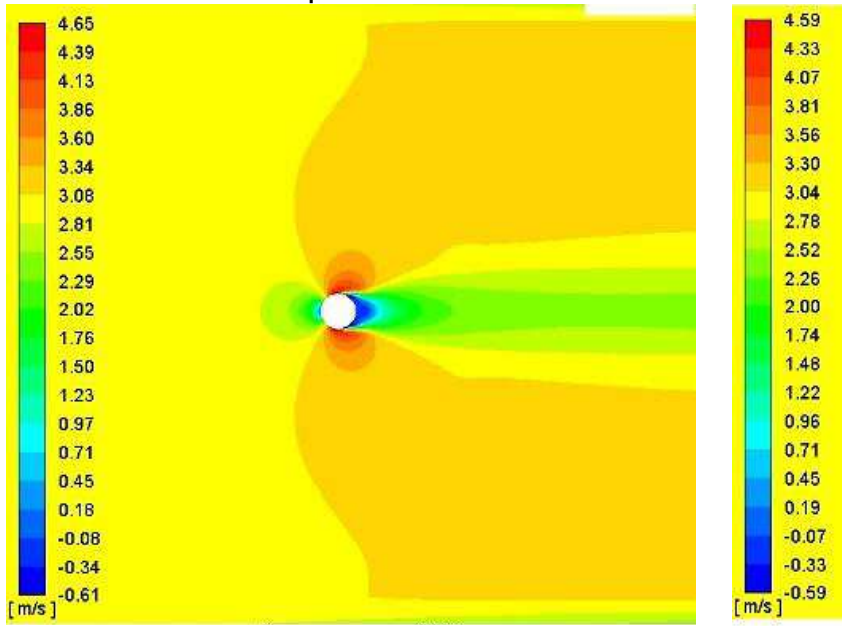

Fig. 8: Mean stream velocity for the selected cases from Table 3.

tri-67

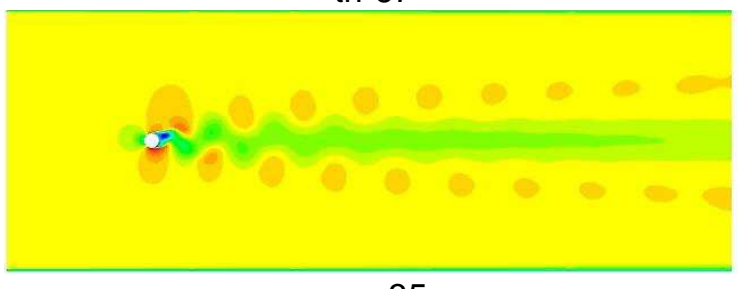

qua-35

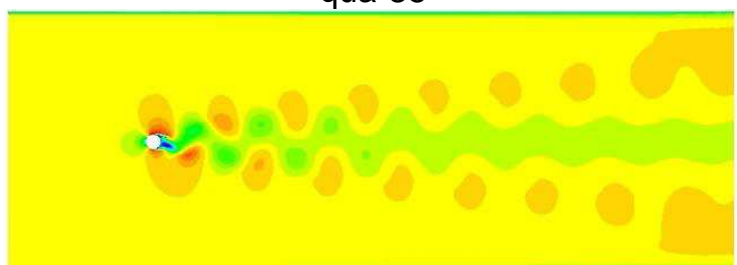

tri-72

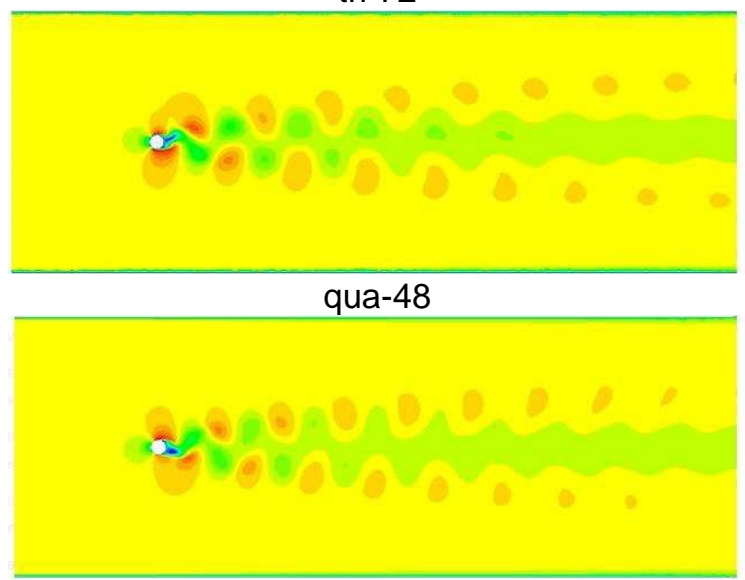

Fig. 9: Velocity $x$ for the selected cases from Table 3.

The Table 4 shows the range of the mean stream velocity and mean velocity magnitude for selected grids and time steps. These values come out similarly for all the grids being solved. 
Table 4: Ranges of mean stream velocity and mean velocity magnitude.

\begin{tabular}{|c|c|c|c|}
\hline grid & $\begin{array}{c}\text { time step } \\
{[\mathrm{s}]}\end{array}$ & $\begin{array}{c}\text { mean stream velocity range } \\
{\left[\mathrm{ms}^{-1}\right]}\end{array}$ & $\begin{array}{c}\text { mean velocity magnitude range } \\
{\left[\mathrm{ms}^{-1}\right]}\end{array}$ \\
\hline tri-67 & 0.0025 & $(-0.50,4.55)$ & $(0,4.74)$ \\
\hline tri-72 & 0.017 & $(-0.60,4.81)$ & $(0,4.97)$ \\
\hline qua-35 & 0.017 & $(-0.61,4.69)$ & $(0,4.87)$ \\
\hline qua-48 & 0.008 & $(-0.59,4.59)$ & $(0,4.79)$ \\
\hline
\end{tabular}

The normalized mean stream velocity is the ratio of the mean stream velocity to the velocity inlet $u_{0}$ (reference). It is presented in Fig. 10, where the calculated values are compared to the experimental data obtained from literature for $R e=3.9 \cdot 10^{3}[10,11]$ and for $R e=1.4 \cdot 10^{5}$ [12], (one order lower and one order higher than $\mathrm{Re}$ in the current task).

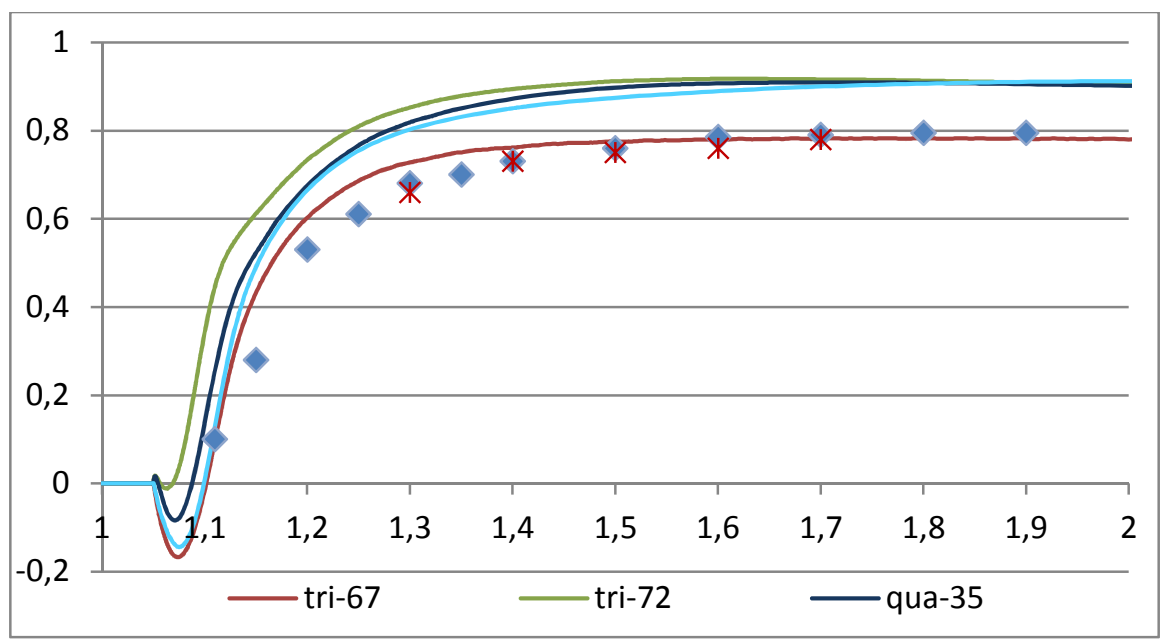

Fig. 10: Normalized mean stream velocity along the wake centreline.

Eddies in the immediate vicinity of the wall behind the cylinder are not presented. They are highly dependent on the type of flow $(\mathrm{Re})$ and therefore are incomparable variables. The results of the two experiments at $1.3 \mathrm{~m}$ from the inlet $(0.3 \mathrm{~m}$ from the axis of the cylinder) are close and they can therefore be compared with the results of the numerical tasks presented in this paper. The grid tri-67 is most advantageous from the point of view of the velocity field. The calculations in the other grids show higher stream-wise velocity than the experimental measurements.

The position of the minimal values of the normalized mean stream velocity is in the same place behind the cylinder wall for three grids, only the tri-72 grid is slightly displaced closer to the wall of the cylinder. These values cannot be compared with experiments, since in these positions the results of the experiments are not fully recorded in the literature for relevant Re numbers.

Also noteworthy is the shape of eddies in the immediate vicinity of the wall behind the cylinder. The stream velocity reaches the positive values at grids of tri-72 and qua-35, which is not described in any of the experiments [10 - 12].

\section{Conclusions}

This comparative study verified the suitability of the SST $k-\omega$ model on the flow past a circular cylinder in 2D for the high Reynolds number. The paper compared the results of drag and lifts coefficients with the respect of different types of meshes and time steps. The mean velocity field in the wake region behind the cylinder has been evaluated and compared to experimental data available from literature.

There were tested four different grids, two consisted of mainly triangular cells and two were formed by quadrilateral cells. All grids showed similar results at the evaluation of the mean stream 
velocity range and the magnitude velocity range (Table 4). The normalized mean stream velocity in the wake of the mesh tri-67 was the closest to the experimental data, the other grids showed smaller differences (Fig. 10). The effect of the time step and the shape of the grid on the results were proved for all grids (Table 2 and Fig. 5). The grids tri-67 and qua-35 were sufficiently accurate compared to the expected value of drag coefficient from literature; there were differences at the evaluation of lift coefficients (Table 2). The requirement of symmetrical oscillation was reached at all tested grids, except for the tri-72 grid where the time recording of the lift coefficient was slightly unbalanced, the recommended interval exceeded in all cases except of grid tri-67.

All grids had fine meshes where $y+<1$, so near wall modelling approach has been used. The biggest difference in the calculation was due to a different way of meshing. In conclusion, it can be evaluated, that the selected SST $k-\omega$ model is a suitable tool for numerical simulations in 2D for high Reynolds numbers and the best result was achieved by the grid when the most gradual transition from the boundary layer has been made within the meshing.

\section{Acknowledgement}

The paper has been supported by the project of Conceptual development of science and research activities 2018 on the Faculty of Civil Engineering, VŠB - TU Ostrava and by the Ministry of Education, Youth and Sports from the Large Infrastructures for Research, Experimental Development and Innovations project: IT4 Innovations National Supercomputing Center - LM2015070.

\section{References}

[1] ZDRAVKOVICH, M. M.: Flow around Circular Cylinders: A Comprehensive Guide through Flow Phenomena, Experiments, Applications, Mathematical Models, and Computer Simulations. Journal of Fluids Engineering, Vol. 2, 2003, p. 612. https://books.google.cz/books?id=ApAqBIpSTtIC\&hl= cs\&source $=$ gbs navlinks $s$.

[2] HUBOVÁ, O. - KONEČNÁ, L. - LOBOTKA, P.: Influence of walls and ceiling on a wind flow in BLWT tunnel. Applied Mechanics and Materials, Vol. 617, 2014, pp. 257 - 262. Trans Tech Publications Ltd. https://doi.org/10.4028/www.scientific.net/AMM.617.257.

[3] MEDVECKÁ, S. - IVÁNKOVÁ, O. - MACÁK, M. - MICHALCOVÁ, V.: Determination of Pressure Coefficient for a High - Rise Building with Atypical Ground Plan. Civil and Environmental Engineering, Vol. 14, Iss. 2, 2018, pp. 138 - 145. https://doi.org/10.2478/cee-2018-0018.

[4] KORMANIKOVA, E. - KOTRASOVA, K.: Multiscale modelling of liquid storage laminated composite cylindrical tank under seismic load. Composites Part B: Engineering, Vol. 146, 2018, pp. 189 - 197. https://doi.org/10.1016/j.compositesb.2018.03.011.

[5] PATEL, Y.: Numerical Investigation of Flow Past a Circular Cylinder and in a Staggered Tube Bundle Using Various Turbulence Models. Lappeenranta University of Technology, 2010, p. 87. http://lutpub.lut.fi/handle/10024/63863?show=full.

[6] MICHALCOVÁ, V. - LAUSOVÁ, L.: Numerical approach to determination of equivalent aerodynamic roughness of Industrial chimneys. Computers and Structures, Vol. 207, 2018, pp. 187 - 193. https://doi.org/10.1016/j.compstruc.2017.03.013.

[7] KOLOŠ, I. - LAUSOVÁ, L. - MICHALCOVÁ, V.: Comparing wind flow models over a single hill. AIP Conference Proceedings, Vol. 1978, 2018, p. 150014. American Institute of Physics Inc. https://doi.org/10.1063/1.5043805.

[8] BENIM, A. C. - CAGAN, M. - NAHAVANDI, A. - PASAQUALOTTO, E.: RANS Predictions of Turbulent Flow Past a Circular Cylinder over the Critical Regime. Proceedings of the $5^{\text {th }}$ IASME/ WSEAS International Conference on Fluid Mechanics and Aerodynamics, 2007, pp. $232-237$. http://www.wseas.us/e-library/conferences/2007athensmech/papers/565-150.pdf.

[9] ANSYS Fluent Theory Guide, Release 19.2 (ANSYS, Inc., 2018).

[10] ONG, L. - WALLACE, J.: The velocity field of the turbulent very near wake of a circular cylinder. Experiments in Fluids, Vol. 20, Iss. 6, 1996, pp. 441 - 453. https://doi.org/10.1007/BF00189383.

[11] FRÖHLICH, J. - RODI, W. - DEWAN, A. - FONTES, J. P.: Large-Eddy Simulation of the Flow around the Free End of a Circular Cylinder. Springer, Berlin, Heidelberg, 2003, pp. $191-202$. https://doi.org/10.1007/978-3-540-45693-3-12.

[12] CANTWELL, B. - COLES, D.: An experimental study of entrainment and transport in the turbulent near wake of a circular cylinder. Journal of Fluid Mechanics, Vol. 136, 1983, pp. $321-374$. https://doi.org/10.1017/S0022112083002189. 